\title{
PENERAPAN METODE SIMPLE ADDITIVE WEGHTING (SAW) PADA APLIKASI SISTEM PENUNJANG KEPUTUSAN UNTUK PEMELIHARAAN JALAN
}

\author{
M Dedy Rosyadi \\ Fakultas Teknologi Informasi \\ Universitas Islam Kalimantan Muhammad Arsyad Al Banjari Banjarmasin \\ dedyrosyadi@gmail.com
}

\begin{abstract}
ABSTRAK
Peneletian ini merancang suatu Aplikasi Sistem Penunjang Keputusan yang menerapkan Metode Simple Additive Weighting (SAW) untuk membantu memberikan rekomendasi dalam pengambilan keputusan pemeliharaan data jalan berdasarkan output yang dihasilkan oleh sistem.

Metode Simple Additive Weighting (SAW) merupakan metode yang paling dikenal dan paling banyak digunakan orang dalam menghadapi situasi MADM (multiple attribute decision making). Dalam penelitian ini metode SAW digunakan untuk mencari nilai akhir pada setiap data jalan. Nilai akhir pada data jalan yang dihasilkan adalah proses perhitungan berdasarkan nilai bobot kriteria yang telah ditentukan. Setiap kriteria mempunyai sub kriteria yang juga mempunyai nilai bobot. Hasil nilai akhir akan disortir (Z-A) artinya nilai tertinggi adalah jalan yang direkomendasikan untuk dilakukan pemeliharaan jalan.
\end{abstract}

Kata Kunci : Metode SAW, Sistem Penunjang Keputusan, Jalan.

\section{PENDAHULUAN}

Jalan merupakan akses yang menghubungkan satu tempat dengan tempat yang lainnya. Jalan juga merupakan media trasportasi yang menjadi salah satu faktor pendukung yang sangat penting untuk melakukan berbagai macam aktivitas kegiatan dan memperlancar roda perekonomian serta mempengaruhi semua aspek dalam kehidupan.

Untuk memperlancar semua aktivitas kegiatan tersebut tentu sangat diperlukan kegiatan pemeliharaan jalan yang dilakukan oleh pemerintah dan instansi terkait, hal ini dimaksudkan agar jalan tersebut dapat menjadi lebih baik dan nyaman sehingga pengguna jalan dapat melakukan aktivitasnya dengan lancar. Jenis pemeliharaan jalan sudah diatur oleh Peraturan Menteri Pekerjaan Umum Nomor : 13/PRT/M/2011 tentang cara pemeliharaan dan penilikan jalan.

Untuk itu diperlukan suatu sistem sebagai alat bantu dalam pengolahan data dan melakukan penilaian jalan sesuai dengan data jalan yang ada di lapangan sehingga hasil penilaian dari sistem ini dapat dijadikan sebagai rekomendasi dalam melakukan pengambilan keputusan dalam menentukan pemeliharaan jalan.

Data rekomendasi yang dihasilkan yaitu data jalan yang ada di Kota Banjarbaru. Proses penilaian yang dilakukan yaitu menerapkan Metode Simple Additive Weighting (SAW). Metode Simple 
Additive Weighting (SAW) adalah salah satu metode pengambilan keputusan yang memberikan solusi dalam pengambilan keputusan, dalam penelitian ini metode simple additive weighting (SAW) digunakan untuk memberikan rekomendasi kepada pengguna dalam menentukan jalan mana yang layak untuk dilakukan pemeliharaan.

Nilai akhir pada data jalan yang dihasilkan adalah proses perhitungan berdasarkan kriteria yang telah ditentukan. Kriteria tersebut mempunyai nilai bobot yang telah ditetapkan sesuai tingkat kepentingan. Setiap kriteria mempunyai sub kriteria yang juga mempunyai nilai sesuai tingkat kepentingan. Hasil nilai akhir akan dirangking (sort Z-A) artinya nilai tertinggi adalah jalan yang direkomendasikan layak untuk dilakukan pemeliharaan jalan. Data tersebut dapat disimpan, diolah, dan disajikan dalam bentuk laporan serta terkomputerisasi sehingga memudahkan dalam pendataan.

\section{IDENTIFIKASI MASALAH}

Berdasarkan latar belakang masalah di atas, penulis mengidentifikasikan permasalahan yaitu :

Bagaimana aplikasi sistem penunjang keputusan dapat membantu sebuah instansi dalam memberikan rekomendasi data jalan yang akan dijadikan prioritas untuk dilakukan pemeliharaan jalan. Rekomendasi data jalan didapatkan melalui proses dari metode yang sebelumnya diberikan nilai bobot pada setiap data jalan sesuai dengan kriteria yang ditentuka.

\section{BATASAN MASALAH}

Aplikasi yang dibuat hanya mengelola data jalan kota Banjarbaru yang setelah di proses menggunakan metode SAW berdasarkan kriteria yang sudah ditentukan nilainya sesuai tingkat kepentingan, akan menghasilkan data jalan yang telah disortir (Z-A). Data jalan dapat di tampilkan melalui peta menggunakan aplikasi Map Info.

\section{TUJUAN}

Tujuan dari penelitian ini adalah untuk membantu pegawai/staff dalam mengambil suatu keputusan untuk menentukan jalan yang dijadikan sebagai prioritas untuk dilakukan pemeliharaan jalan berdasarkan data hasil rekomendasi yang dihasilkan dari system yang dibuat.

\section{MANFAAT}

Manfaat yang dibisa di gunakan dari penelitian ini adalah membantu pengguna dalam mengambil suatu keputusan berdasarkan rekomendasi yang dihasilkan dari sistem untuk dijadikan acuan dalam menentukan jalan mana yang akan dilakukan pemeliharaan lebih dulu sesuai dengan kriteria yang telah ditentukan dan memudahkan pihak pengguna dalam melakukan pengelolaan data dan mencari informasi yang diperlukan.

\section{ANALISIS SISTEM}

Tujuan dari analisa sistem ini adalah untuk menentukan masalah dalam upaya memperbaiki sistem, menganalisa sistem program dan menyesuaikan dengan program yang akan dibuat agar benar-benar dapat digunakan sesuai dengan kebutuhan.

Hasil yang bisa diperoleh dengan adanya sistem yang di buat ini berupa kemudahan dalam pengolahan data dan menampilkan laporan-laporan yang diperlukan (Output). Sehingga kebutuhan akan sistem informasi data menjadi lebih lengkap dan lebih terstruktur.

\section{PERANCANGAN SISTEM}

Tahap perancangan Analisa Sistem ini terbagi menjadi beberapa bagian yaitu : 
a. Membuat rancangan database beserta tabel yang akan digunakan pada aplikasi sistem penunjang keputusan yang kemudian di sesuaikan dengan kebutuhan data.

b. Perancangan Diagram Konteks dan Data Flow Diagram untuk menggambarkan alur proses data.

c. Perancangan antarmuka pada aplikasi.

\section{ALAT DAN BAHAN}

Sebelum mengimplementasikan program, yang dibutuhkan adalah kebutuhan sistem, dimana terdiri dari perangkat keras dan perangkat lunak.

1. Perangkat Keras

Perangkat keras yang dibutuhkan untuk implementasi adalah:

Laptop dengan spesifikasi :

Processor minimal core i3, ram 2GB, hardisk minimal $160 \mathrm{~GB}, \mathrm{VGA}$ dengan resolusi 1366 x 768 .

2. Perangkat Lunak (Software)

1. Sistem operasi (OS) windows 7

2. Borland Delphi 7

3. Map Info Profesional

4. Database Ms. Access

\section{SISTEM PENDUKUNG KEPUTUSAN}

SPK sebagai sebuah sistem berbasis komputer yang membantu dalam proses pengambilan keputusan. SPK sebagai sistem informasi berbasis komputer yang adaptif, interaktif, fleksibel, yang secara khusus dikembangkan untuk mendukung solusi dari pemasalahan manajemen yang tidak terstruktur untuk meningkatkan kualitas pengambilan keputusan.

Dengan demikian dapat ditarik satu definisi tentang SPK yaitu sebuah sistem berbasis komputer yang adaptif, fleksibel, dan interaktif yang digunakan untuk memecahkan masalah-masalah tidak terstruktur sehingga meningkatkan nilai keputusan yang diambil. (Khoirudin, 2008).

Dari definisi tersebut dapat diindikasikan empat karakteristik utama dari SPK, yaitu :

1. SPK menggabungkan data dan model menjadi satu bagian

2. SPK dirancang untuk membantu para manajer (pengambil keputusan) dalam proses pengambil keputusan dari masalah yang bersifat semi struktural (atau tidak terstruktur).

3. SPK lebih cenderung dipandang sebagai penunjang penilaian manajer dan sama sekali bukan untuk menggantikannya.

4. Teknik SPK dikembangkan untuk meningkatkan efektivitas dari pengambil keputusan.

\section{FMADM}

FMADM adalah suatu metode yang digunakan untuk mencari alternatif optimal dari sejumlah alternatif dengan kriteria tertentu. Inti dari FMADM adalah menentukan nilai bobot untuk setiap atribut, kemudian dilanjutkan dengan proses perankingan yang akan menyeleksi alternatif yang sudah diberikan. Pada dasarnya, ada 3 pendekatan untuk mencari nilai bobot atribut, yaitu pendekatan subyektif, pendekatan obyektif dan pendekatan integrasi antara subyektif \& obyektif.

\section{METODE SIMPLE ADDITIVE WEIGHTING}

Metode Simple Additive Weighting (SAW) sering juga dikenal istilah metode penjumlahan terbobot. Konsep dasar metode SAW adalah mencari penjumlahan terbobot dari rating kinerja pada setiap alternatif pada semua atribut (Fishburn, 1967) (MacCrimmon, 1968). Metode SAW membutuhkan proses normalisasi matriks keputusan (X) ke suatu skala yang dapat diperbandingkan dengan semua rating alternatif yang ada. 
Formula untuk menentukan normalisasi adalah sebagai berikut :

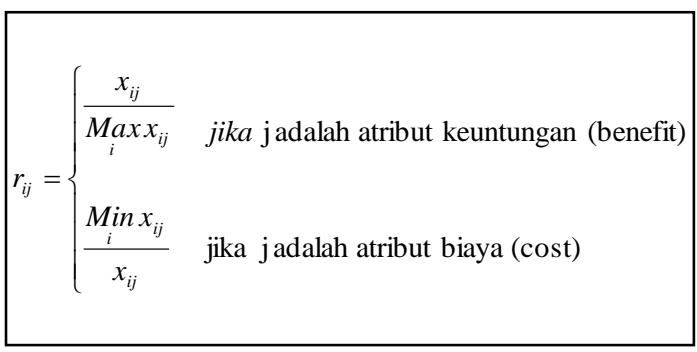

$\mathbf{r}_{\text {ij }} \quad$ : Rating kinerja ternormalisasi

Maxi : Nilai maksimum dari setiap baris dan kolom

Min $_{\mathbf{i}}$ : Nilai minimum dari setiap baris dan kolom

$\mathbf{X}_{\mathbf{i j}} \quad$ : Baris dan kolom dari matriks

$$
V_{i}=\sum_{j=1}^{n} w_{j} r_{i j}
$$

$\mathbf{V}_{\mathbf{i}} \quad$ : Nilai akhir dari Alternatif

$\mathbf{W}_{\mathbf{i}} \quad$ : Bobot yang telah ditentukan

$\mathbf{r}_{\mathrm{ij}} \quad$ : Normalisasi matriks

Nilai $\mathrm{V}_{\mathrm{i}}$ yang lebih besar mengindikasikan bahwah alternatif $A_{i}$ lebih terpilih.

\section{PROSES PERHITUNGAN}

1. Data jalan berdasarkan kriteria yang dipilih

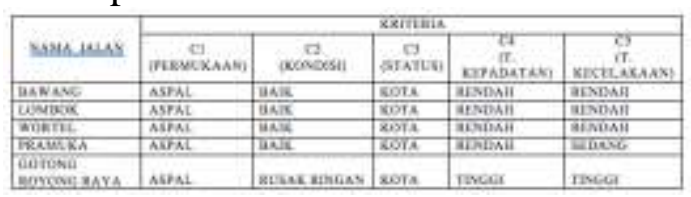

Gambar 1 Data Jalan

2. Konversi nilai bobot

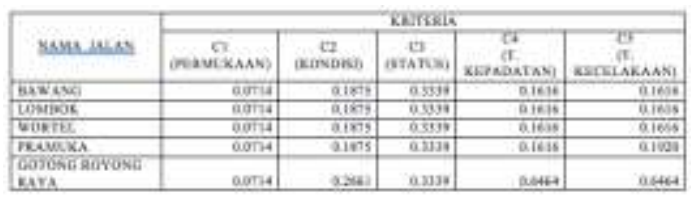

Gambar 2 Konversi nilai bobot

3. Proses Perhitungan

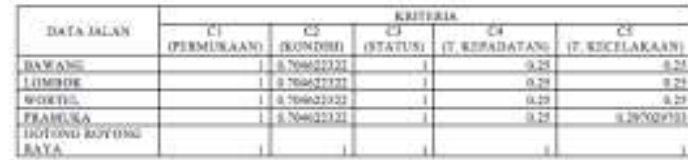

Gambar 3 Proses Perhitungan

4. Nilai Akhir

\begin{tabular}{|l|r|}
\hline \multicolumn{1}{|c|}{ DATA JALAN } & \multicolumn{1}{c|}{ NILAI AKHIR } \\
\hline BAWANG & 0.740496561 \\
\hline LOMBOK & 0.740496561 \\
\hline WORTEL & 0.740496561 \\
\hline PRAMUKA & 0.743934433 \\
\hline GOTONG ROYONG RAYA & 1 \\
\hline
\end{tabular}

Gambar 4 Nilai Akhir

Setelah melalui perhitungan menggunakan metode SAW hasil yang di dapatkan adalah jalan gotong royong raya mendapat nilai tertinggi, artinya jalan tersebut lebih di rekomendasikan diantara 5 data jalan yang ada.

\section{HASIL PENELITIAN IMPLEMENTASI}

Setelah membuat semua tahapan perancangan, tahapan selanjutnya adalah masuk ke tahapan proses implementasi sistem. Berikut ini beberapa form yang di buat berdasarkan hasil perancangan antar muka.

1. Form Login

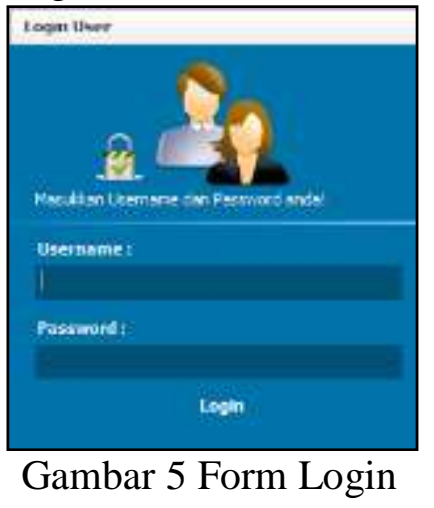


2. Menu Utama

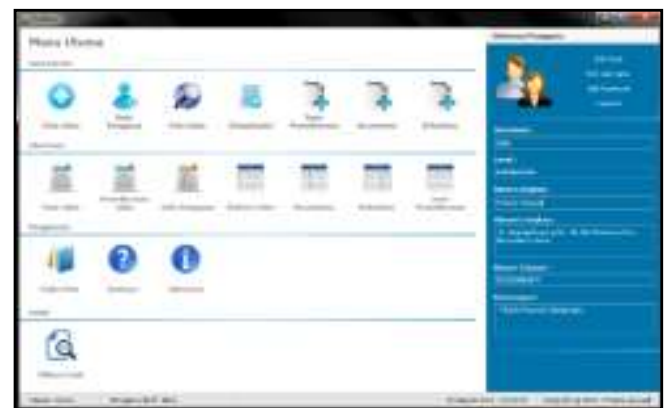

Gambar 6 Menu Utama

3. Form Pengguna

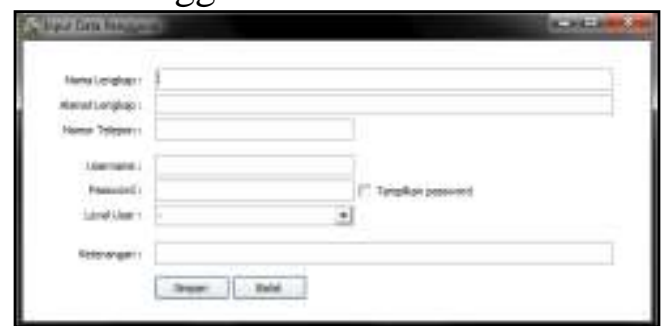

Gambar 7 Form Pengguna

4. Form Kecamatan

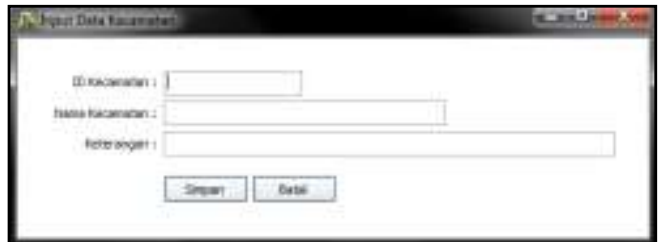

Gambar 8 Form Kecamatan

5. Form Kelurahan

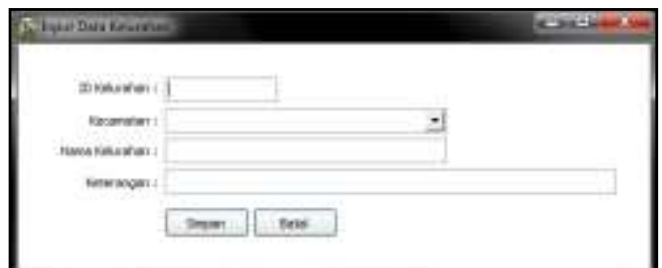

Gambar 9 Form Kelurahan

6. Form Jenis Pemeliharaan

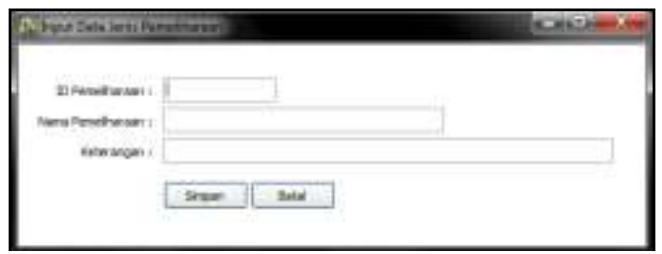

Gambar 10 Form Jenis

Pemeliharaan
7. Form Jalan

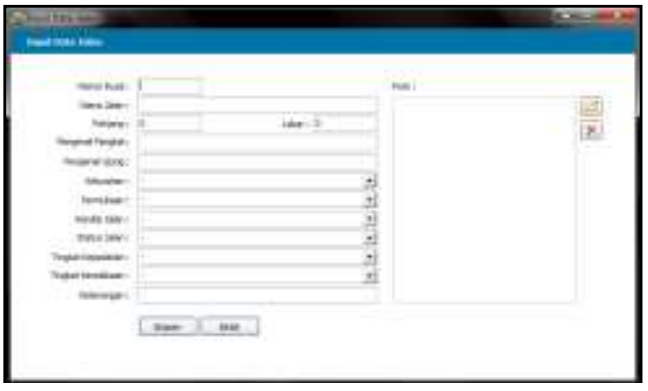

Gambar 11 Form Jalan

8. Form Pemeliharaan Jalan

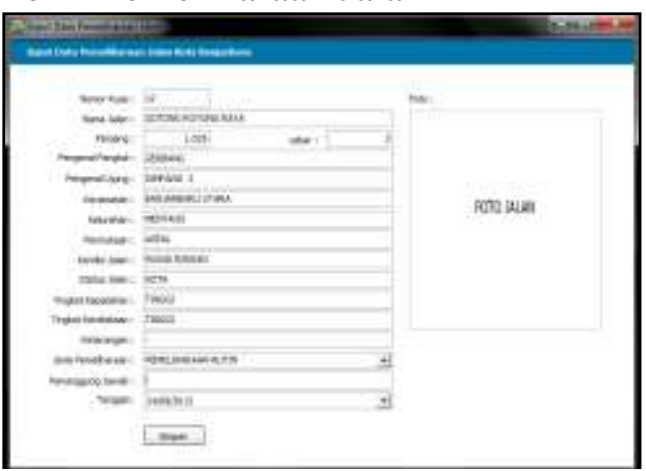

Gambar 12 Form Pemeliharaan Jalan

9. Form Kriteria

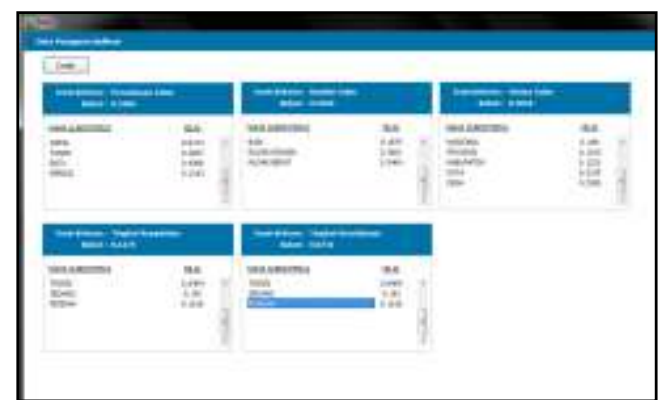

Gambar 13 Form Kriteria

10. Form Tampilan Peta

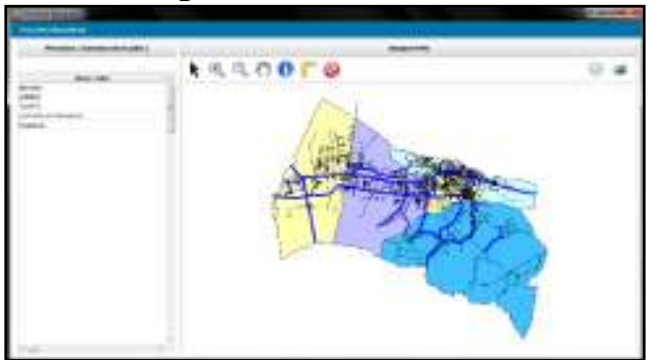

Gambar 14 Form Tampilan Peta 
11. Form Rekapitulasi

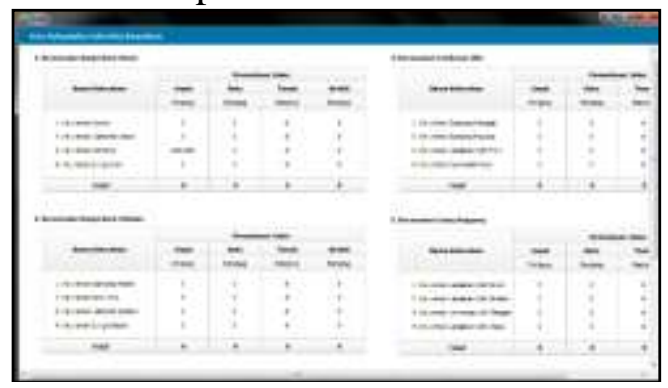

Gambar 15 Form Rekapitulasi

12. Laporan Data Jalan

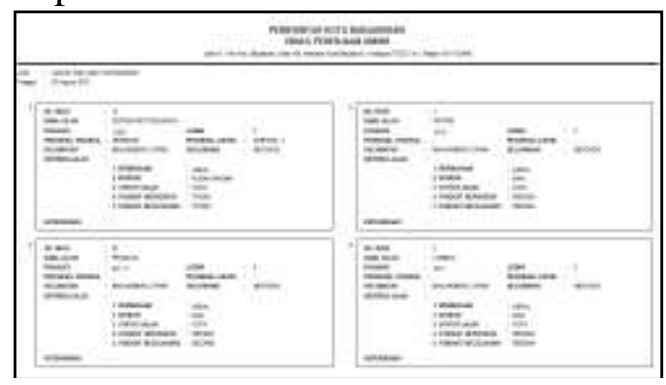

Gambar 16 Laporan Data Jalan

\section{PENUTUP}

\section{KESIMPULAN}

Berdasarkan pembahasan yang penulis uraikan pada bab-bab sebelumnya, maka dapat ditarik kesimpulan serta saran yang nantinya diharapkan berguna dan bermanfaat.

1. Output yang dihasilkan dari aplikasi ini adalah berupa nilai yang sebelumnya dilakukan proses perhitungan, untuk menghasilkan nilai tersebut digunakan metode Simple Additive Weighting.

2. Nilai bobot kriteria dan sub kriteria didapatkan melalui proses perhitungan manual dengan menggunakan metode AHP. Setelah nilai bobot kriteria dan sub kriteria didapatkan kemudian akan dilanjutkan lagi dengan proses perhitungan melalui metode SAW untuk mendapatkan nilai akhir.

3. Output dari aplikasi ini bisa dikatakan sebagai rekomendasi oleh sistem untuk user dan dapat dijadikan acuan untuk membantu dalam pengambilan keputusan secara cepat tetapi keputusan akhir tetap melalui manajer / atasan pada instansi tersebut.

4. Data jalan dapat dilihat pada peta sehingga memudahkan user dalam melakukan pencarian letak jalan sesuai data peta yang telah tersedia

\section{DAFTAR PUSTAKA}

Ir. Inge Martina. 2004. 36 Jam Belajar Komputer Pemprograman Visual Borland Delphi.

Kadir, Abdul. 2005. Pemrograman Database dengan Delphi 7.0 Menggunakan Access.

Peraturan Daerah Kota Banjarbaru nomor 14 Tahun 2011 tentang Rencana Pembangunan Jangka Menengah (RPJM) Daerah Kota Banjarbaru Tahun $2011-2015$.

Peraturan Menteri Pekerjaan Umum Nomor : 13 /PRT/M/2011 Tentang Tata Cara Pemeliharaan Dan Penilikan Jalan Dengan Rahmat Tuhan Yang Maha Esa Menteri Pekerjaan Umum.

Peraturan Pemerintah Republik Indonesia Nomor 34 Tahun 2006 Tentang Jalan

Sri Kusumadewi, Hari Purnomo (2004). Aplikasi Logika Fuzzy Untuk Mendukung Keputusan. Yogyakarta: Graha Ilmu.

Sri Kusumadewi, Sri Hartati, Agus Harjoko, Retantyo Wardoyo (2006). Fuzzy Multi Attribut Decision Making (Fuzzy MADM) Yogyakarta: Graha Ilmu.

Undang-Undang Republik Indonesia Nomor 38 Tahun 2004 Tentang Jalan

http://gisforumgps.blogspot.com/2010/01/mapinf o.html diakses tanggal 30 Desember 2012

http://id.wikipedia.org/wiki/MapInfo_Pr ofessional diakses tanggal 30 Desember 2012 
http://id.wikipedia.org/wiki/Sistem_pend ukung keputusan diakses tanggal 1 Januari 2013

http://widyawarta.wordpress.com/2010/0 6/21/gis-mapinfo/ diakses tanggal 5 Februari 2013

http://www.worldfriend.web.id/blogfriend/567-definisi-sisteminformasi--teknologi-informasi-danilmu-pengetahuan diakses tanggal 5 Februari 2013 